\title{
Protective effect of fennel, and its major component trans-anethole against social isolation induced behavioral deficits in rats
}

\author{
S. RAMAN, M. ASLE-ROUSTA* (D) and M. RAHNEMA
}

Department of Physiology, Zanjan Branch, Islamic Azad University, Zanjan, Iran

Received: August 13, 2019 • Accepted: February 05, 2020

Published online: April 14, 2020

(c) 2020 Akadémiai Kiadó, Budapest

\section{ABSTRACT}

Social isolation damages the nervous system by weakening the antioxidant system and leading to behavioral disorders. Fennel (Foeniculum vulgare Mill.) is an herbal plant that has antioxidant and neuroprotective properties. The objective of this study was to evaluate the effect of fennel methanol extract and its major component trans-anethole on spatial learning and memory, anxiety and depression in male rats exposed to social isolation stress.

Rats were divided into six groups of Control (C), Fennel (F), trans-Anethole (A), Isolation, Isolation-F and Isolation-A. The rats were kept in the cage alone for 30 days to induce isolation. Fennel extract (150 $\mathrm{mg} / \mathrm{kg}$ ) and trans-anethole $(80 \mathrm{mg} / \mathrm{kg})$ were also gavaged during this period. At the end of the course, spatial learning and memory, anxiety and depression were measured by Morris water maze (MWM), elevated plus maze (EPM) and forced swimming test (FST), respectively.

Learning and memory were impaired in isolated rats. Swimming time and distance to reach the hidden platform in these animals increased compared with controls $(P<0.05)$. In the EPM test, the percentage of open arm entries and open arm time also decreased significantly in the Isolation group $(P<0.01)$. The immobilization time in FST also increased significantly in these animals compared with the Control group $(P<0.001)$. Fennel and trans-anethole were both able to eliminate these changes in isolated rats.

It is concluded that fennel and its major component, trans-anethole are suitable candidates for the prevention and treatment of stress-induced neurological disorders.

\section{KEYWORDS}

Fennel (Foeniculum vulgare Mill.), trans-anethole, memory, anxiety, depression, social isolation

\footnotetext{
*Corresponding author. Tel.: +98 9125606327. E-mail: mrousta@iauz.ac.ir
} 


\section{INTRODUCTION}

For social creatures isolation is a type of stress that increases sympathetic tone, stimulates hypothalamic-pituitary-adrenal axis activation, and increases glucocorticoid production [4]. Increase in glucocorticoids affects the brain (especially the hippocampus and the cortex). Decreased activity of superoxide dismutase, catalase and glutathione peroxidase antioxidant enzymes and increased levels of hydrogen peroxide (indicating oxidative stress in these areas), production of inflammatory factors, impaired cholinergic system, decreased glutamate and glutamine levels, and long-term potentiation (LTP) attenuation in the cornu ammon 1 (CA1) region are the consequences of social isolation $[14,15,25,33]$, which cause behavioral disorders such as memory deficits, anxiety and depression [20, 21, 38, 39].

Fennel (Foeniculum vulgare Mill.) is a plant of the family Apiaceae. The methanol extract of fennel seed contains rich amounts of trans-anethole, and estragole is the second most abundant compound in this plant. It is also rich in phenolic compounds (such as quinic acid, 4-O-caffeoylquinic acid, p-coumaric acid, and 4-O-caffeoylquinic acid), therefore the plant's antioxidant properties have been attributed to these compounds and it has been reported that the antioxidant activity of the methanol extract of fennel is more than that of its essential oil $[1,13]$. The anti-diabetic [24] and neuroprotective [2] properties of fennel have also been reported. Transanethole (a phenol methyl ether) is the most abundant compound present in fennel which has antioxidant [35], anti-inflammatory [18], hepato-protective [7] and neuro-protective [31] properties. Given these effects, we hypothesized that fennel and trans-anethole could reduce behavioral disorders induced by social isolation stress. Therefore, the objective of the present study was to investigate the effect of the methanol extract of fennel and trans-anethole on memory impairment, anxious behavior and depression induced by social isolation in adult male rats.

\section{MATERIAL AND METHODS}

\section{Fennel extraction}

F. vulgare Mill. was bought from a local store and approved by botanists at Zanjan Azad University Biological Research Center. Two hundred grams of fennel seed powder was soaked in $600 \mathrm{ml}$ of methanol for $48 \mathrm{~h}$ and shaken continuously during this time. After passing through the filter, the solution was dried with water bath heat and finally, the required doses of the extract were prepared by adding distilled water [32].

\section{Animals and experimental design}

Adult male Wistar rats weighing 200-220 g were purchased from Pasteur Institute (Tehran, Iran) and kept in standard laboratory conditions. The experiments were conducted in accordance with the ethics of working with laboratory animals approved by Islamic Azad University on June 19, 2017 (Number: IR.IAU.Z.REC.1396,30). Before the beginning of the study, rats were kept in groups of four in each cage for one week. Then animals were divided into six groups randomly (each group of 10 rats) including: 
1. Control (intact, C).

2. Fennel (F) (Received fennel methanol extract at a dose of $150 \mathrm{mg} / \mathrm{kg}$ ) [32].

3. trans-Anethole (A) (trans-anethole - purchased from Sigma Aldrich (USA) - received at a dose of $80 \mathrm{mg} / \mathrm{kg})$ [37].

4. Isolation (each rat was kept in a cage $-24 \times 13.5 \times 13 \mathrm{~cm}-$ alone for 30 consecutive days and had no visual or tactile contact with the other rats) [25].

5. Isolation-F (received fennel extract in addition to isolation).

6. Isolation-A (received trans-anethole in addition to isolation).

Non-isolated rats continued to be housed in groups of four in each cage $(42 \times 27 \times 15 \mathrm{~cm})$. The cages of isolated and non-isolated groups were housed in the same room and their access to food and water was the same.

Fennel extract or trans-anethole (diluted in distilled water to $0.4 \mathrm{ml}$ per rat) were fed to animals for 30 days by gavage using a needle, and each animal was monitored for $5 \mathrm{~min}$ after gavage. Spatial learning and memory of the animals were assessed by using Morris water maze (MWM) on days 26-30 and one day after the end of the course, anxious behavior and depression were measured by elevated plus maze (EPM) and forced swimming test (FST), respectively, on two occasions in the morning and in the afternoon respectively.

\section{Morris water maze test}

MWM test was performed in two stages. In the first phase, which lasted for four consecutive days, rats were placed in a water tank $(130 \mathrm{~cm}$ in diameter and $60 \mathrm{~cm}$ in height) and found a hidden circular platform $(10 \mathrm{~cm}$ in diameter) by using signs around the tank four times each day (90 s each time). The inner wall of the tank and the platform were painted black and the platform was placed $2 \mathrm{~cm}$ below the water's surface. The test was performed in low light, so the rats could not see the platform. Rats were placed in the tank and sat on the platform for $20 \mathrm{~s}$ after finding the platform or ending the 90-s period. If the animal could not find the platform, it would be directed to the platform by the researcher. Immediately after the end of the 20 -s sitting time on the platform, the next trial began. The swimming activity of each animal was monitored by a camera on top of the tank and then analyzed by MazeRouter software (Tabriz, Iran). The decrease in swimming time $(\mathrm{s})$ and spent distance $(\mathrm{cm})$ to find the platform indicates learning in the animal. The second phase was performed one day after the end of the first phase. Each animal swam in the water tank without a platform for $60 \mathrm{~s}$. Increase in time spent in the quarter where the platform was placed in the first stage means memory improvement of the rat [3].

\section{Elevated plus maze test}

After the end of the 30-day period, each animal was studied only once for $5 \mathrm{~min}$ in the EPM test. The EPM is made up of four arms - two open arms $(50 \times 10 \mathrm{~cm})$ and two closed arms $(50 \times 10 \times 30 \mathrm{~cm})$ - that form a plus $(+)$ and is placed $50 \mathrm{~cm}$ above the ground. The number of arms entries and the length of time spent in each arm were recorded. Increase in the 
percentage of open arm entry (OAE) and time spent in open arm (OAT) means anxiety reduction in the animal [3].

\section{Forced swimming test}

In the FST, each animal was placed in a plexiglass column $(45 \mathrm{~cm}$ high and $20 \mathrm{~cm}$ in diameter) containing water up to a height of $17 \mathrm{~cm}$ for $6 \mathrm{~min}$. The first $2 \mathrm{~min}$ were used to accustom the rat to the test and the immobilization time of the animal was measured in the next $4 \mathrm{~min}$. The decrease in total immobility indicates depression reduction in the animal [16].

\section{Statistical analysis}

Statistical analyses were performed using SPSS v. 16. Data are expressed as means \pm SEM relative to control. Data were assessed by one-way ANOVA followed by Tukey HSD test for post-hoc comparisons between groups. Repeated measurements were used to compare changes in time and distance to reach the platform within 4 days in each group. For all tests, $P<0.05$ was considered significant.

\section{RESULTS}

The results of repeated tests showed that the time and distance traveled to reach the hidden platform in all groups decreased gradually from day 1 to day $4(P<0.001)$. The results of the MWM test also confirmed that spatial learning and memory were impaired in the Isolation group. The time spent and the distance traveled to reach the hidden platform on day 4 were significantly higher in the Isolation group than in the Control group $(P<0.05)$. Transanethole and fennel extract both reduced these factors in isolated rats $(P<0.05)$. In the second phase, the Isolation group swam less time in the target quarter than the control group $(P<$ $0.01)$, whereas trans-anethole and fennel extract increased the time spent by isolated rats in the target quarter $(P<0.05)$. Groups $\mathrm{F}$ and $\mathrm{A}$ did not significantly differ from the Control group (Fig. 1).

The results of the EPM test also showed anxious behavior in rats of the Isolation group. The percentage of OAT and OAE in these animals was significantly reduced compared with the Control group $(P<0.01)$, whereas trans-anethole and fennel extract both increased the OAT and OAE percentage in the isolated animals $(P<0.05)$. Groups $\mathrm{A}$ and $\mathrm{F}$ did not differ significantly from the controls (Table 1).

According to the results of FST, isolation increased immobilization time compared with the Control group and indicated depression in these animals $(P<0.001)$. Administration of fennel extract and trans-anethole significantly decreased immobilization time in isolated rats $(P<0.001$ and $P<0.01$, respectively), but immobilization in groups $\mathrm{A}$ and $\mathrm{F}$ was not significantly different from the Control group (Fig. 2). 

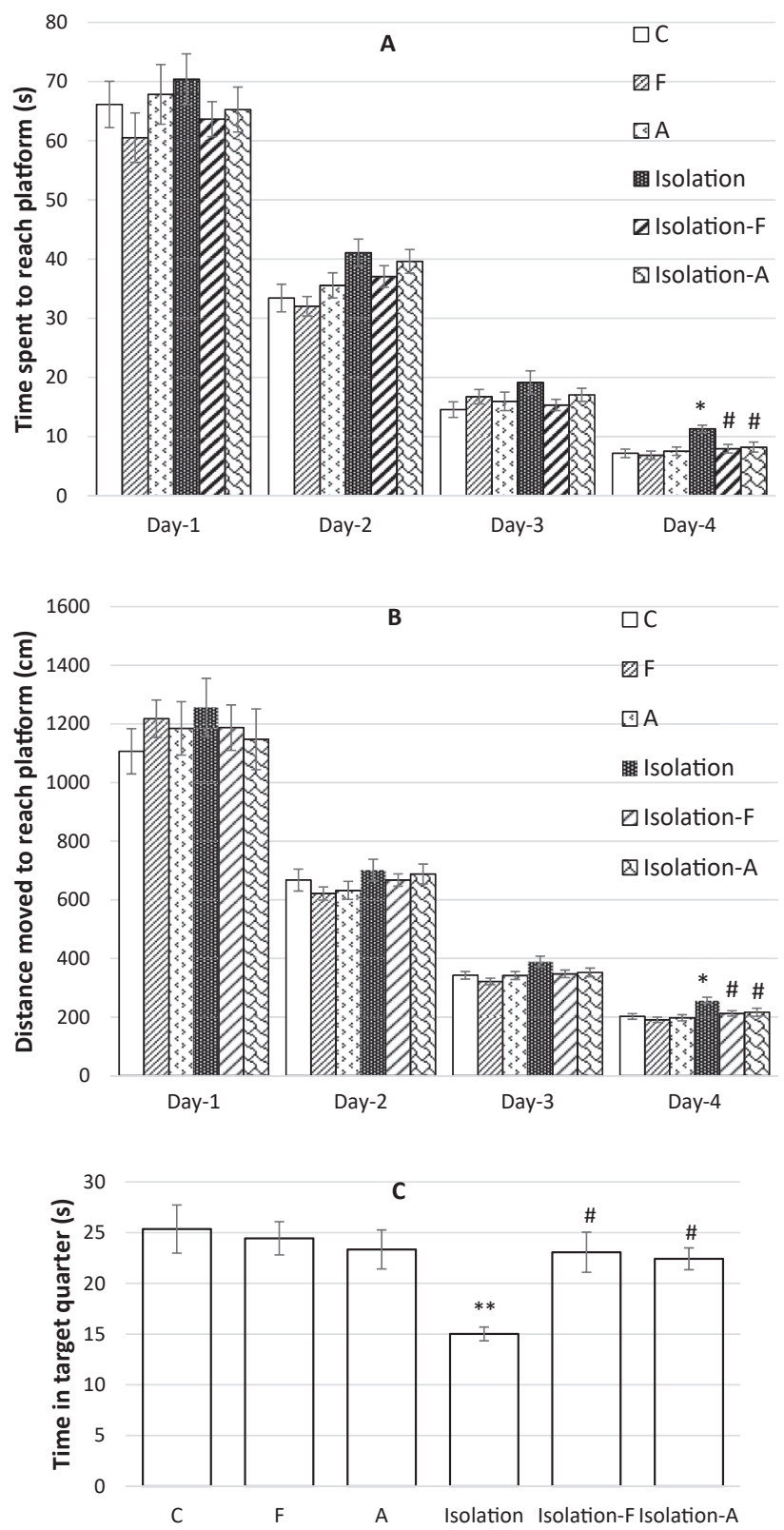

Figure 1. (A) Time spent and (B) distance moved to reach the hidden platform in Morris water maze test. Each column represents the average of 4 trainings per day. (C) Time spent in target quarter in second phase. Results are presented as mean \pm SEM. ${ }^{*} P<0.05$ and ${ }^{* *} P<0.01$ vs. Control group and ${ }^{\#} P<0.05$ vs. Isolation group. $(n=10)$ 
Table 1. The results of animal anxiety evaluation using the Elevated Plus Maze (EPM)

\begin{tabular}{lcc}
\hline Group & OAT \% & OAE \% \\
\hline C & $51.70 \pm 2.83$ & $50.38 \pm 1.34$ \\
Fennel (F) & $40.10 \pm 4.62$ & $49.16 \pm 1.00$ \\
trans-Anethole (A) & $47.89 \pm 4.74$ & $48.92 \pm 2.56$ \\
Isolation & $26.63 \pm 3.73^{*}$ & $39.87 \pm 2.08^{* *}$ \\
Isolation-F & $47.49 \pm 6.17 \#$ & $47.72 \pm 1.01 \#$ \\
Isolation-A & $45.99 \pm 3.86 \#$ & $47.44 \pm 1.51 \#$ \\
\hline
\end{tabular}

The percentage of open arm entry (OAE) and open arm time (OAT) were calculated in EPM and the results are presented as mean \pm SEM. ${ }^{*} P<0.05,{ }^{* *} P<0.01$ vs. Control group and ${ }^{*} P<0.05$ vs. Isolation group. $(n=10)$.

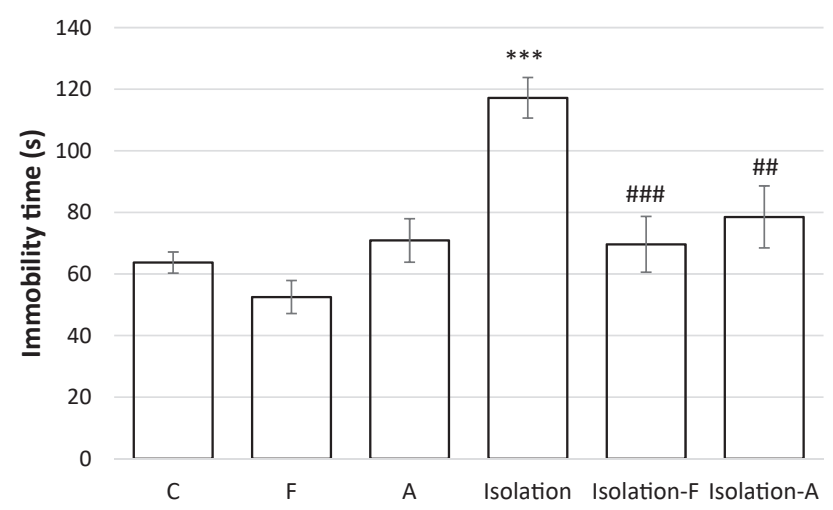

Figure 2. Total amount of immobility time in forced swimming test. Results are presented as means \pm SEM. Each group contained 10 rats. ${ }^{* * *} P<0.001$ vs. Control group and ${ }^{\# \#} P<0.01,{ }^{\# \# \#} P<0.001$ vs. Isolation group. $(n=10)$

\section{DISCUSSION}

In the present study, 30 days of social isolation caused learning and memory impairment, and emergence of anxious behaviors and depression in rats, which is consistent with results from previous studies [11, 20, 42]. According to the MWM test results, fennel and trans-anethole consumption improved spatial learning and memory in isolated rats. It is reported that 8-day treatment with methanol extract of whole fennel plants increased step-down latency in rats by inhibiting acetylcholinesterase activity [12]. Recently, the anticholinesterase effect of transanethole has also been demonstrated [35]. After isolating compounds from the hooks of Uncaria rhynchophylla, Suk-Chul and Dong-Ung [38] found in 2013 that this plant is rich in transanethole and (to a lesser extent) estragole. Trans-anethole improves the performance of scopolamine-treated rats in the MWM test and passive avoidance task system, and rats' performance was better than that of rats treated with tacrine, a central cholinesterase inhibitor. On the other hand, fennel ethanol extract strengthens the antioxidant system in the cortex and 
hippocampus of lead-receiving mice and reduces the expression of amyloid precursor protein in these regions [2]. Trans-anethole also suppresses oxygen-glucose deprivation/reoxygenationinduced reactive oxygen species overproduction in cortical neurons [31]. In addition to transanethole, other compounds found in fennel also affect memory. For example, p-coumaric acid suppresses $\beta$-amyloid-induced toxicity in PC12 cells by inhibiting inflammation and suppressing NF- $\kappa$ B signaling [40] and by enhancing LTP in the hippocampus of scopolaminetreated rats, and it improves the performance of these animals in the MWM test [17]. Quinic acid derivatives also rescue PC12 cells from $\beta$-amyloid-induced toxicity and stimulate neurite outgrowth in these cells [10]. Therefore, trans-anethole and fennel extract could improve learning and memory of isolated rats, possibly by strengthening the antioxidant system, cholinesterase inhibition, and LTP enhancement in the hippocampus.

Isolated rats that received trans-anethole and fennel extract also performed better in the EPM test compared with the Isolation group, with a significantly higher percentage of OAE and OAT. This result is in line with a report by Pourabbas et al. [29] regarding the anti-anxiety effect of fennel extract (stimulated by $\mathrm{GABA}_{\mathrm{A}}$ ). Consumption of oil from this plant for 3 weeks improves the performance of rats in the EPM test as well [28]. Fennel also reduces anxiety in postmenopausal women [8]. After separating trans-anethole from verum fruit oil, Miyagawa et al. [22] demonstrated the anti-anxiety effect of this compound. In addition to trans-anethole, other compounds in fennel also reduce anxiety. For example, by enhancing the activity of the GABAergic system, feeding with leaves containing p-coumaric acid has anti-anxiety effects on rodents [34]. Opposite effects of other fennel compounds have also been observed. For example, despite the anti-anxiety effect of Croton zehntneri essential oil, its derivative estragol (also abundant in fennel) reduces the total time of social interaction which means emergence of anxiety-related behavior [6].

FST results showed a decrease in total immobilization time in isolated rates treated with transanethole and fennel extract, indicating a decrease in depression in these animals. There are similar results in this regard. For example, fennel oil treatment for 3 weeks has an antidepressant effect in rats (similar to fluoxetine) [28]. Fennel consumption also leads to depression reduction in postmenopausal women [8]. Mona et al. [23] showed that fennel extract treatment after 4 weeks resulted in increased levels of serotonin, dopamine, and norepinephrine in different brain regions including the cortex, the brainstem and the hippocampus. Given the importance of monoamines in the treatment of depression [9], fennel extract seems to decrease depression in isolated rats by increasing the levels of these neurotransmitters. There is no report on the effect of trans-anethole on depression, but results have been reported for other existing compounds in fennel. Cosentino et al. [6] reported that $C$. zehntneri-derived estragole had no effect on depression in rats, whereas p-coumaric acid reduced lipopolysaccharide-induced depression in rats by decreasing inflammatory cytokines and increasing brain-derived neurotrophic factor in the hippocampus [19].

Oxidative stress and inflammation also play important roles in memory disorder, anxiety, and depression caused by social stress [27]. Considering the antioxidant and anti-inflammatory effects of fennel and trans-anethole [1, 13, 18, 32], caffeoylquinic acid [41], quinic acid [10] and estragole [30], it seems that reduction in behavioral disturbances caused by social isolation through consuming fennel and trans-anethole is related to some extent to strengthening the antioxidant system and reducing neuronal inflammation in these animals.

Studies have shown that social isolation causes structural, functional, and behavioral changes in the human brain and increases the risk of neurodegenerative diseases, thus increases the risk of mortality. These effects are mainly due to increased levels of glucocorticoids that lead to 
decreased inflammatory control and altered neurotransmission of monoamines and neuropeptides in brain $[5,26,36]$. Since social isolation has almost similar effects on the human and animal brain, the use of medicinal plants and their compounds may also be helpful in reducing stress-induced effects in the human brain. The results of the present study suggest a suitable plant in this regard, although further studies are needed, especially in the molecular field.

Finally, it is concluded that fennel and trans-anethole are effective in reducing behavioral deficits caused by social isolation, therefore they may be appropriate options for the prevention and treatment of stress-related behavioral disorders.

Conflict of interest: None of the authors have conflicts of interest.

\section{ACKNOWLEDGMENTS}

Authors thank Ms. Mina Hossein-Zadeh for help with behavioral tests.

\section{REFERENCES}

1. Alam P, Abdel-Kader MS, Alqarni MH, Zaatout HH, Ahamad SR, Shakeel F. Chemical composition of fennel seed extract and determination of fenchone in commercial formulations by GC-MS method. J Food Sci Technol. 2019; 56: 2395-403, https://doi.org/10.1007/s13197-019-03695-9.

2. Bhatti S, Ali Shah SA, Ahmed T, Zahid S. Neuroprotective effects of Foeniculum vulgare seeds extract on lead-induced neurotoxicity in mice brain. Drug Chem Toxicol. 2018; 41: 399-407, https://doi.org/10.1080/ 01480545.2018.1459669.

3. Bigdeli Y, Asle-Rousta M, Rahnema M. Effects of limonene on chronic restraint stress-induced memory impairment and anxiety in male rats. Neurophysiology. 2019; 51: 107-13, https://doi.org/10.1007/s11062019-09800-0.

4. Cacioppo JT, Cacioppo S, Capitanio JP, Cole SW. The neuroendocrinology of social isolation. Annu Rev Psychol. 2015; 66: 733-67, https://doi.org/10.1146/annurev-psych-010814-015240.

5. Cacioppo JT, Hawkley LC, Norman GJ, Berntson GG. Social isolation. Ann N Y Acad Sci. 2011; 1231: 17-22, https://doi.org/10.1111/j.1749-6632.2011.06028.x.

6. Cosentino RM, Norte MC, Lazarini CA. Estragole-induced behavioural changes in rats. Phytother Res. 2004; 18: 921-24, https://doi.org/:10.1002/ptr.1583.

7. da Rocha BA, Ritter AM, Ames FQ, Gonçalves OH, Leimann FV, Bracht L, et al. Acetaminophen-induced hepatotoxicity: preventive effect of trans anethole. Biomed Pharmacother. 2017; 86: 213-20, https://doi.org/ 10.1016/j.biopha.2016.12.014.

8. Ghazanfarpour M, Mohammadzadeh F, Shokrollahi P, Khadivzadeh T, Najaf Najafi M, Hajirezaee H, et al. Effect of Foeniculum vulgare (fennel) on symptoms of depression and anxiety in postmenopausal women: a double-blind randomised controlled trial. J Obstet Gynaecol Res. 2018; 38: 121-6, https://doi.org/10.1080/ 01443615.2017.1342229.

9. Haenisch B, Bönisch H. Depression and antidepressants: insights from knockout of dopamine, serotonin or noradrenaline re-uptake transporters. Pharmacol Ther. 2011; 129: 352-68, https://doi.org/10.1016/j. pharmthera.2010.12.002.

10. Hur JY, Soh Y, Kim BH, Suk K, Sohn NW, Kim HC, et al. Neuroprotective and neurotrophic effects of quinic acids from Aster scaber in PC12 cells. Biol Pharm Bull. 2001; 24: 921-4, https://doi.org/10.1248/bpb.24.921. 
11. Ieraci A, Mallei A, Popoli M. Social isolation stress induces anxious-depressive-like behavior and alterations of neuroplasticity-related genes in adult male mice. Neural Plast. 2016; 2016: 6212983, https://doi.org/10. 1155/2016/6212983.

12. Joshi H, Parle M. Cholinergic basis of memory-strengthening effect of Foeniculum vulgare Linn. J Med Food. 2006; 9: 413-7, https://doi.org/10.1089/jmf.2006.9.413.

13. Kalleli F, Bettaieb Rebey I, Wannes WA, Boughalleb F, Hammami M, Saidani Tounsi M, et al. Chemical composition and antioxidant potential of essential oil and methanol extract from Tunisian and French fennel (Foeniculum vulgare Mill.) seeds. J Food Biochem. 2019; 43: e12935, https://doi.org/10.1111/jfbc.12935.

14. Kamal A, Ramakers GM, Altinbilek B, Kas MJ. Social isolation stress reduces hippocampal long-term potentiation: effect of animal strain and involvement of glucocorticoid receptors. Neuroscience. 2014; 256: 262-70, https://doi.org/10.1016/j.neuroscience.2013.10.016.

15. Karelina K, Norman GJ, Zhang N, Morris JS, Peng H, DeVries AC. Social isolation alters neuroinflammatory response to stroke. Proc Natl Acad Sci U S A. 2009; 106: 5895-900, https://doi.org/10.1073/pnas.0810737106.

16. Keshavarzi S, Kermanshahi S, Karami L, Motaghinejad M, Motevalian M, Sadr S. Protective role of metformin against methamphetamine induced anxiety, depression, cognition impairment and neurodegeneration in rat: the role of CREB/BDNF and Akt/GSK3 signaling pathways. Neurotoxicology. 2019; 72: 74-84, https://doi. org/10.1016/j.neuro.2019.02.004.

17. Kim HB, Lee S, Hwang ES, Maeng S, Park JH. p-Coumaric acid enhances long-term potentiation and recovers scopolamine-induced learning and memory impairments. Biochem Biophys Res Commun. 2017; 492: 493-9, https://doi.org/10.1016/j.bbrc.2017.08.068.

18. Kim KY, Lee HS, Seol GH. Anti-inflammatory effects of trans-anethole in a mouse model of chronic obstructive pulmonary disease. Biomed Pharmacother. 2017; 91: 925-30, https://doi.org/10.1016/j.biopha.2017.05.032.

19. Lee S, Kim HB, Hwang ES, Kim ES, Kim SS, Jeon TD, et al. Antidepressant-like effects of p-Coumaric acid on LPS-induced depressive and inflammatory changes in rats. Exp Neurobiol. 2018; 27: 189-99, https://doi.org/ 10.5607/en.2018.27.3.189.

20. Li N, Yu M, Cui L, Song G, Guo L, Gu H, et al. Adolescent isolation interacts with DISC1 point mutation to impair adult social memory and synaptic functions in the hippocampus. Front Cell Neurosci. 2018; 12: 238, https://doi.org/10.3389/fncel.2018.00238.

21. Malkesman O, Maayan R, Weizman A, Weller A. Aggressive behavior and HPA axis hormones after social isolation in adult rats of two different genetic animal models for depression. Behav Brain Res. 2006; 175: 408-14, https://doi.org/10.1016/j.bbr.2006.09.017.

22. Miyagawa M, Satou T, Yukimune C, Ishibashi A, Seimiya H, Yamada H, et al. Anxiolytic-like effect of illicium verum fruit oil, trans-anethole and related compounds in mice. Phytother Res. 2014; 28: 1710-2, https://doi. org/10.1002/ptr.5190.

23. Mona AR, Seham M, Amira AB. Study on the effect of fennel extract on some neurotransmitters. Bull Fac Sci Cairo Univ. 2010; 78: 1-29.

24. Mostafa DM, El-Alim SH, Asfour MH, Al-Okbi SY, Mohamed DA, Awad G. Transdermal nanoemulsions of Foeniculum vulgare Mill. essential oil: preparation, characterization and evaluation of antidiabetic potential. J Drug Deliv Sci Technol. 2015; 29: 99-106, https://doi.org/10.1016/j.jddst.2015.06.021.

25. Motoyama K, Nakai Y, Miyashita T, Fukui Y, Morita M, Sanmiya K, et al. Isolation stress for 30 days alters hepatic gene expression profiles, especially with reference to lipid metabolism in mice. Physiol Genomics. 2009; 37: 79-87, https://doi.org/10.1152/physiolgenomics.90358.2008.

26. Okada R, Fujiwara H, Mizuki D, Araki R, Yabe T, Matsumoto K. Involvement of dopaminergic and cholinergic systems in social isolation-induced deficits in social affiliation and conditional fear memory in mice. Neuroscience. 2015; 299: 134-45, https://doi.org/10.1016/j.neuroscience.2015.04.064. 
27. Patki G, Solanki N, Atrooz F, Allam F, Salim S. Depression, anxiety-like behavior and memory impairment are associated with increased oxidative stress and inflammation in a rat model of social stress. Brain Res. 2013; 1539: 73-86, https://doi.org/10.1016/j.brainres.2013.09.033.

28. Perveen T, Emad S, Ahmad S, Batool Z, Yousuf S, Sheikh S, et al. Fennel oil treatment mimics the antidepressive and anxiolytic effects of fluoxetine without altering the serum cholesterol levels in rats. Pak J Zool. 2017; 49: 2291-7, https://doi.org/10.17582/journal.pjz/2017.49.6.2291.2297.

29. Pourabbas S, Kesmati M, Rasekh A. Study of the anxiolytic effects of fennel and possible roles of both GABAergic system and estrogen receptors in these effects in adult female rat. Physiol Pharmacol. 2011; 15: 134-43.

30. Roy A, Park HJ, Jung HA, Choi JS. Estragole exhibits anti-inflammatory activity with the regulation of NF- $\kappa$ B and Nrf-2 signaling pathways in LPS-induced RAW 264.7 cells. Nat Prod Sci. 2018; 24: 13-20, https://doi.org/ 10.20307/nps.2018.24.1.13.

31. Ryu S, Seol GH, Park H, Choi IY. Trans-anethole protects cortical neuronal cells against oxygen-glucose deprivation/reoxygenation. Neurol Sci. 2014; 35: 1541-7, https://doi.org/10.1007/s10072-014-1791-8.

32. Sadrefozalayi S, Farokhi F. Effect of the aqueous extract of Foeniculum vulgare (fennel) on the kidney in experimental PCOS female rats. Avicenna J Phytomed. 2014; 4: 110-7, https://doi.org/10.22038/AJP.2014. 1824.

33. Sandi C, Haller J. Stress and the social brain: behavioural effects and neurobiological mechanisms. Nat Rev Neurosci. 2015; 16: 290-304, https://doi.org/10.1038/nrn3918.

34. Scheepens A, Bisson JF, Skinner M. p-Coumaric acid activates the GABA-A receptor in vitro and is orally anxiolytic in vivo. Phytother Res. 2014; 28: 207-11, https://doi.org/10.1002/ptr.4968.

35. Shahriari M, Zibaee A, Sahebzadeh N, Shamakhi L. Effects of $\alpha$-pinene, trans-anethole, and thymol as the essential oil constituents on antioxidant system and acetylcholine esterase of Ephestia kuehniella Zeller (Lepidoptera: Pyralidae). Pestic Biochem Physiol. 2018; 150: 40-7, https://doi.org/10.1016/j.pestbp.2018.06.015.

36. Shao Y, Yan G, Xuan Y, Peng H, Huang QJ, Wu R, et al. Chronic social isolation decreases glutamate and glutamine levels and induces oxidative stress in the rat hippocampus. Behav Brain Res. 2015; 282: 201-8, https://doi.org/10.1016/j.bbr.2015.01.05.

37. Sheikh BA, Pari L, Rathinam A, Chandramohan R. Trans-anethole, a terpenoid ameliorates hyperglycemia by regulating key enzymes of carbohydrate metabolism in streptozotocin induced diabetic rats. Biochemie. 2015; 112: 57-65, https://doi.org/10.1016/j.biochi.2015.02.008.

38. Suk-Chul SH, Dong-Ung LE. Ameliorating effect of new constituents from the hooks of Uncaria rhynchophylla on scopolamine-induced memory impairment. Chin J Nat Med. 2013; 11: 391-5, https://doi.org/10. 1016/S1875-5364(13)60057-6.

39. Walker DM, Cunningham AM, Gregory JK, Nestler EJ. Long-term behavioral effects of post-weaning social isolation in males and females. Front Behav Neurosci. 2019; 13: 66, https://doi.org/10.3389/fnbeh.2019.00066.

40. Yoon JH, Youn K, Ho CT, Karwe MV, Jeong WS, Jun M. p-Coumaric acid and ursolic acid from corni fructus attenuated $\beta$-Amyloid25-35-induced toxicity through regulation of the NF- $\kappa \mathrm{B}$ signaling pathway in PC12 cells. J Agric Food Chem. 2014; 62: 4911-6, https://doi.org/10.1021/jf501314g.

41. Zhang Z, Liu Y, Ren X, Zhou H, Wang K, Zhang H, Luo P. Caffeoylquinic acid derivatives extract of Erigeron multiradiatus alleviated acute myocardial ischemia reperfusion injury in rats through inhibiting NF-KappaB and JNK activations. Mediat Inflamm. 2016; 2016: 7961940, https://doi.org/10.1155/2016/7961940.

42. Zorzo C, Méndez-López M, Méndez M, Arias JL. Adult social isolation leads to anxiety and spatial memory impairment: brain activity pattern of COX and c-Fos. Behav Brain Res. 2019; 365: 170-7, https://doi.org/10. 1016/j.bbr.2019.03.011. 